\title{
STAKEHOLDER PERCEPTIONS OF THE BENEFITS AND BARRIERS OF IMPLEMENTING ENVIRONMENTAL MANAGEMENT SYSTEMS IN THE NIGERIAN CONSTRUCTION INDUSTRY
}

\author{
Victoria O. OWOLANA ${ }^{1}$, Colin A. BOOTH ${ }^{2}$ \\ ${ }^{1}$ Department of Architecture and the Built Environment, Faculty of Environment and Technology, \\ University of the West of England, Bristol BS16 1QY, UK \\ ${ }^{2}$ Department of Architecture and the Built Environment, Faculty of Environment and Technology, \\ University of the West of England, Bristol BS16 1QY, UK
}

Submitted 13 Apr. 2015; accepted 30 Nov. 2015

\begin{abstract}
This study investigates stakeholder opinions of the major benefits and barriers of Environmental Management Systems (EMS) to the Nigerian construction industry, and the perceived issues to EMS adoption among organisations in the industry. The study highlights the environment as an important stakeholder in the industry because it affects and is affected by construction activities on a regular basis. It identifies the importance of ISO 14001 in ensuring adequate consideration for the environment is maintained on construction projects. The research adopts a quantitative approach by analysing responses from an online survey among construction industry professionals in Nigeria. The questions on the survey were drawn from a similar study carried out in Asia and the results were analysed using the Weighted Average and Standard Deviation statistical approach. Results reveal that the major benefits of EMS to the Nigerian construction industry were improved efficiency in waste management and environmental protection, as well as an overall increase in employee motivation due to better opportunities for training and development. Lack of technological support in organisations and the high cost of implementing EMS were viewed as the major barriers towards its uptake in construction companies. The findings also indicate that a feasible EMS implementation strategy must not ignore the unique nature of the Nigerian construction industry, which comprises mostly small and medium enterprises. The study concludes by recommending the use of a waste management plan based on the Reuse-ReduceRecycle-Recover model and an employee training plan to ensure continuous improvement in the organisation's environmental management strategy.
\end{abstract}

Keywords: ISO 14001, corporate responsibility, sustainability, environmental management, construction, Nigeria.

\section{Introduction}

Sustainability has become an important factor in today's world, and huge importance is increasingly attached to the environment as a stakeholder in major construction industries (Haigh, Griffiths 2009; Hammond, Booth 2010; Medineckiene et al. 2010). Many construction projects have included sustainability as one of their key performance indicators (Fewings 2013); productivity and progress are often based on the ability to meet several environmental criteria. According to Chan and Chan (2004), it appears that the industry is no longer just focusing on maximising value for money for the client. Preserving the environment has undoubtedly become part of the social responsibility of organisations towards the global community (Castka, Balzarova 2008).

An Environmental Management System (EMS) is a tool that helps organisations to manage and positively improve their level of impact on the environment (Christini et al. 2004; Oke 2004). An EMS helps a company measure its environmental performance and provides the framework for the integration of sustainable development goals within the organisation's corporate plan (Ilinitch et al. 1998; Jolevski 2013). Typically, an EMS is made up of policies, goals, plans, regulatory requirements and is usually reflected in the company's annual reports. Christini et al. (2004) gives the following basic characteristics for an organisation's EMS: (i) goals, methods and a timeline for

Corresponding author: Victoria O. Owolana

E-mail: victoria.owolana@gmail.com 
achieving environmental criteria; (ii) procedures for maintaining a paper trail in relation to those goals; (iii) a defined structure and a matrix of responsibilities, as well as allocated resources; (iv) corrective actions and emergency procedures; (v) employee training plan; and (vi) a plan for monitoring and auditing the organisation's performance in achieving the EMS goals.

The earliest set of standard EMS was released by the British Standards Institution in 1992 as the standard BS7750 'Specification for Environmental Management Systems'. BS7750 was designed to complement the European regulation, Eco-management and Audit Scheme, which had also been launched by the EU in the mid-90s (Bohoris, O’Mahony 1994; Wenk 2004). One of the current, most widely used and recognised standards for environmental management is the ISO 14001 . This is a specification document that forms part of the ISO 14000 series designed for the purposes of audit and specification by the International Organisation for Standardisation (ISO) (Zhang et al. 2000). Christini et al. (2004) compared ISO 14001 to an integrated management system that streamlines the policies, documentation, data collection, auditing of quality, environmental, and health and safety management systems. In essence, ISO 14001 provides guidelines that can improve the management portfolio of any type of organization in any country and not just their environmental performance (Morrow, Rondinelli 2002).

As evidence of the importance of EMS in large construction related organisations: (i) Rio Tinto Plc demonstrates a commitment to maintaining their responsibility to their stakeholders by ensuring that risks related to social wellbeing, environmental stewardship and economic prosperity are understood and managed (Rio Tinto 2008). This commitment has formed the foundation of their business conduct and their sustainable development framework is named: 'The way we work. The framework forms part of their EMS, which governs their overarching sustainability strategy (Rio Tinto 2008); (ii) Carillion Plc is one of the international construction companies that have fully integrated their EMS into their wider corporate risk management processes (Carillion Plc 2014). The majority of their establishments in the UK, Middle East and North Africa operate under ISO 14001 (Carillion Plc 2014); and (iii) The British Standards Institution (BSI) has also published a case study of Costain Plc, a leading British engineering and construction firm, which shows that the implementation of ISO 14001 has helped in reducing the amount of waste generated by $53 \%$ and $93 \%$ has been diverted from landfill in the last four years (BSI Group 2014).

Industrial sectors have been slow to embrace EMS in Africa and, moreover, most construction companies have simply failed to engage with EMS. Therefore, the purpose of this study is to explore the opinions of construction professionals towards their perceptions of the benefits and barriers of implementing EMS in the Nigerian construction industry, so as to identify a strategy for improved organisational ownership of sustainable issues.

\section{Environmental management systems in the African construction industry}

The paradigm shift towards the implementation of environmental management in Africa is gradually gaining significance (Aminu et al. 2010). This has materialised out of the need for an environmentally conscious approach within the construction industry, which accounts for a large percentage of development in Africa. Adebayo (2002) pointed out that the driving force was best explained by the Amsterdam Treaty in 1997, which takes on an all-encompassing approach to sustainable development and encourages an integrated approach in managing and implementing environmental policies that affect the economy, leading to parallel progress in all the relevant fields. In other words, the underlying idea of sustainable construction in Africa is the fuel that drives development within the construction industry, which is one of the most productive sectors in Africa (Ofori 2006; Medineckiene et al. 2010). It could, therefore, be said that the environment is a primary stakeholder in the economic development of Africa, especially in the area of construction (Marzouk et al. 2013).

Haigh and Griffiths (2009) justified the case for considering the environment as a stakeholder by approaching this from a strategic viewpoint because the environment is not only affected by an organisation but affects it, hence solidifying Freeman's (1984) criteria. However, when the influence of the environment is examined with respect to climate change, it is seen as possessing powerful, legitimate, urgent and proximate properties, all of which qualify it as a primary stakeholder (Haigh, Griffiths 2009). In this sense, the natural environment has a strong economic stake in the affairs of businesses, organisations and governments (Dixon et al. 2007; Medineckiene et al. 2010).

There are multiple benefits to be reaped through the implementation of EMS in African construction organisations. Ofori (1998) suggested that one major benefit is the ease with which effective construction waste management can be achieved using EMS frameworks and standards. This will amount in notable cost savings and reduce many health, safety and environmental risks that may arise during the course of any project (Ofori 1998; Jolevski 2013). Shen and Tam (2002) also noted that effective waste management would lead to reduced hazardous waste generated from both onsite and offsite construction processes.

Adebayo (2002) explained that in spite of obvious benefits of environmental management and the international legislation and guidelines that are available, few African countries have succeeded in making remarkable strides in 
this area. There is still a consistent gap between theory and practice in most African nations and between legislation and implementation (Ofori 2006). Many of the construction companies have failed to implement the necessary adjustments and progress is still remarkably slow compared to the rest of the world (Adebayo 2002).

Hill and Bowen (1997) noted that the initial implementation of the environmental management framework in South Africa was voluntary because it enabled the solutions to the issues of implementing sustainability in construction to be tested in the African environment before consequently being assimilated into a legal agenda. However, Adebayo (2002) explained that in African countries, like Nigeria, a number of construction project stakeholders in Africa chose to neglect the more important aspects of protection and quality of the environment and focus more on the economic angle. As such, there is still a slow rate of progress in terms of the adoption of EMS in $\mathrm{Ni}$ geria, even though it is one of the largest economies in Africa, alongside South Africa (BBC News 2014). Only 44 companies have been equipped with ISO 14001 certifications (ISO 2012) and a large percentage of these are multinational corporations (Windapo, Jegede 2013). Moreover, many of these organisations view this certification as a diploma earned after an examination, rather than as a process that needs to be implemented and improved upon (Boiral, Sala 1998).

Du Plessis (2005) suggested that one reason for this lapse in sustainable development in Africa is that many policies do not take into account the unique nature of the African environment and the differences in the way the construction industry is structured across various parts of the continent. The appropriateness of many EMS measures does not take into account the local economic conditions especially the reliability of key infrastructure services. Moreover, the EMS framework needs to be embedded into organisational culture and government policy (Balzarova et al. 2004).

Windapo and Jegede (2013) explained that the majority of the construction companies in Nigeria are small and medium enterprises. Many of the EMS standards are tailor made to be implemented by large and well established organisations and it is difficult to apply them in smaller companies (Sjostrom, Bakens 1999). This may be due to the high initial cost implication of implementing the environmental management framework (Oke 2004; Ervin et al. 2013), which was identified as a major barrier to EMS implementation in a similar study in Ghana (Famiyeh et al. 2014).

Adebayo (2002) argued that in order to bridge this conflict between theory and practice, policies need to be tailored to suit the African context. Current research in the African built environment is now shifting in this direction. Adegbite (2013) demonstrated that various aspects of established systems from other economies can be scrutinised and analysed to determine best practice for a developing economy such as Nigeria.

Nigeria, officially the Federal Republic of Nigeria is often referred to as "the Giant of Africa", due to its large population and economy (Holmes 1985). Nigeria has been identified as a regional power in Africa, with its economy (Gross Domestic Production (GDP)) becoming the largest in Africa with more than $\$ 500$ billion, overtaking South Africa and becoming the world's 26th largest economy (BBC News 2014). The Nigerian construction industry contributes a substantial amount to the GDP of the economy and is mostly made up of small and medium indigenous companies, while a majority of the larger companies are managed by international organisations (Idoro 2012).

\section{Methods}

A survey method was chosen to explore the opinions of construction professionals towards their perceptions of the benefits and barriers of implementing EMS in the Nigerian construction industry. The questions were adapted from a similar study carried out by Shen and Tam (2002). The questionnaire was compiled and administered using an online distribution technique with the aid of Survey Monkey software (www.surveymonkey.com) to 500 construction industry professionals in Nigeria via email. Members of professional bodies were targeted via an online directory of Nigerian Industry professionals (www.nigerianprofessional.com). Respondents were also sourced from tertiary institutions and members of various organisations who have the data of their staff published publicly on their websites.

Forty completed responses were received (an $8 \%$ response rate). Although it is considered a low response rate, it is typical of online surveys carried out in developing countries (Business Day Online 2013). Furthermore, the quality of the Nigerian internet service is known to lead to partial or no response from participants, as explained by Czaja and Blair (2005).

The data was analysed using one of the statistical measurements of central tendency: Mean or Weighted Average. The Weighted Average formula shown in Equation (1) is taken from the same form of analysis performed by Shen and Tam (2002). WAS denotes the Weighted Average Score for each given factor $i, \alpha_{j}$ denotes the numerical value given to each of the ranking categories, where one is allocated to the lowest rank, and five is allocated to the highest rank, $n_{i j}$ denotes the number of respondents for factor $i$ with respect to the ranking category $j$, and $N$ denotes the total number of respondents for the whole question.

$$
W A S_{i}=\frac{\sum_{j=1}^{5}\left(\alpha_{j} n_{i j}\right)}{N} .
$$


Shen and Tam (2002) noted that this formula alone is not sufficient to calculate the ranking of each of the factors. This analysis, therefore, employed the use of a coefficient of variation, which is determined by dividing the $W A S_{i}$ by the standard deviation, which is a recognised measure of dispersion (Naoum 2013). This coefficient was then added to the $W A S_{i}$ to give an adjusted score on which the final ranking was then based. The Adjusted Score formula is shown in Equation (2), where $W A S_{i}$ denotes the score calculated for each factor $i$ and $\delta_{i}$ is the standard deviation for each factor $i$, calculated using the weighted average score.

$$
\text { Adjusted Score }=W A S_{i}+\frac{W A S_{i}}{\delta_{i}} .
$$

\section{Results}

\subsection{Benefits of environmental management systems}

The study presented a set of nine factors, which are considered the benefits of implementing EMS in the

Table 1. Frequency distribution of participant responses to the benefits of implementing EMS in the Nigerian construction industry

\begin{tabular}{cccccc}
\hline $\begin{array}{c}\text { Beneficial } \\
\text { Factor }\end{array}$ & $\begin{array}{c}\text { Large } \\
\text { Extent }\end{array}$ & $\begin{array}{c}\text { Moderate } \\
\text { Extent }\end{array}$ & $\begin{array}{c}\text { Some } \\
\text { Extent }\end{array}$ & $\begin{array}{c}\text { Minimal } \\
\text { Extent }\end{array}$ & $\begin{array}{c}\text { No } \\
\text { Extent }\end{array}$ \\
\hline BF-a & 4 & 7 & 9 & 12 & 6 \\
BF-b & 12 & 9 & 9 & 7 & 1 \\
BF-c & 18 & 7 & 5 & 6 & 2 \\
BF-d & 20 & 7 & 5 & 4 & 2 \\
BF-e & 8 & 9 & 10 & 10 & 1 \\
BF-f & 10 & 9 & 6 & 11 & 2 \\
BF-g & 8 & 13 & 10 & 7 & 0 \\
BF-h & 16 & 10 & 7 & 4 & 1 \\
BF-i & 21 & 4 & 7 & 3 & 3 \\
\hline
\end{tabular}

Table 2. Calculated Average Significant Score (ASS) and Beneficial Index Value (BIV) for participant responses to benefits of implementing EMS in the Nigerian construction industry

\begin{tabular}{ccccc}
\hline BF & ASS & $\delta$ & BIV & BIV $^{\mathrm{R}}$ \\
\hline BF-a & 2.76 & 1.22 & 5.02 & 9 \\
BF-b & 3.63 & 1.18 & 6.71 & 6 \\
BF-c & 3.87 & 1.30 & 6.84 & 5 \\
BF-d & 4.03 & 1.25 & 7.26 & 2 \\
BF-e & 3.34 & 1.15 & 6.24 & 7 \\
BF-f & 3.37 & 1.29 & 5.99 & 8 \\
BF-g & 3.58 & 1.02 & 7.10 & 3 \\
BF-h & 3.95 & 1.12 & 7.46 & 1 \\
BF-i & 3.97 & 1.33 & 6.97 & 4 \\
\hline
\end{tabular}

construction industry. These factors were selected based on a synthesis of relevant literature and were presented to the respondents as follows:

BF-a: Cost saving due to the reduction of fines associated with convictions

BF-b: Improving corporate image in environmental performance

BF-c: Contribution to the improvement of public environmental standards

BF-d: Contribution to environmental protection

BF-e: Increasing overall business competitiveness

BF-f: Reduction of environmental complaints

BF-g: Improving staff work environment, thus increasing their morale

BF-h: Reduction of environment-related sickness and injuries

BF-i: Reduction of environmental risks - polluted air, land and water

Respondents were asked to rank these factors into the following categories: Large Extent, Moderate Extent, Some Extent, Minimal Extent and No Extent. Table 1 gives a summary of the participant responses and the frequency distribution of this ranking. In order to determine the overall highest and lowest ranking factors, the weighted average of each factor was calculated using the formula in Equation (1). The results of this calculation are shown in Table 2, under Average Significant Score (ASS).

The ASS could be used to determine the ranking of each factor. However, the weighted average does not take into account the variation of the individual responses (Shen, Tam 2002) and gives an inaccurate representation of the highest and lowest ranking factors. Therefore, an adjusted score was calculated using the coefficient of variation for each factor, which was calculated with the formula in the figure above. This adjusted score was tagged Beneficial Index Value (BIV). The final ranking of each factor is shown under the column $\mathrm{BIV}^{\mathrm{R}}$ in Table 2.

The final ranking of the factors is, therefore, shown as follows:

BF-h: Reduction of environment-related sickness and injuries

BF-d: Contribution to environmental protection

BF-g: Improving staff work environment, thus increasing their morale

BF-i: Reduction of environmental risks - polluted air, land and water

BF-c: Contribution to the improvement of public environmental standards

BF-b: Improving corporate image in environmental performance

BF-e: Increasing overall business competitiveness

BF-f: Reduction of environmental complaints

BF-a: Cost saving due to the reduction of fines associated with convictions 
Based on the results presented it can be seen that factors BF-h (Reduction of environment-related sickness and injuries), BF-d (Contribution to environmental protection) and BF-g (Improving staff work environment, thus increasing their morale) are deemed the top three benefits of EMS ranked by respondents. The lowest ranking benefits were BF-e (Increasing overall business competitiveness) BF-f (Reduction of environmental complaints) and BF-a (Cost saving due to the reduction of fines associated with convictions) in that order. Figure 1 is a graphical representation of the final ranking.

\subsection{Barriers to environmental management systems}

A list of barriers to implementing EMS in the construction industry was presented to the respondents as follows:

EB-a: Lack of government legal enforcement

EB-b: Increase in management and operation costs

EB-c: Lack of trained staff and expertise

EB-d: Lack of client support

EB-e: Lack of sub-contractor cooperation

EB-f: Lack of supplier co-operation

EB-g: Difficult co-ordination of environmental performance among multi-tier subcontractors

EB-h: Lack of working staff support

EB-i: Time-consuming for improving environmental performance

EB-j: Change of existing practice of company structure and policy

EB-k: Increase in documentation workload

EB-l: Lack of tailor-made training on environmental management

EB-m: Lack of technological support within organisation

Respondents were again asked to rank these factors into the following categories: Large Extent, Moderate Extent, Some Extent, Minimal Extent and No Extent. Table 3 provides a summary of the distribution of the participant responses.

In order to determine the overall highest and lowest ranking factors, the weighted average of each factor was calculated. The results of this calculation are shown in Table 4, under Average Barrier-effect Score (ABS). As in the previous section, an adjusted score was calculated using the coefficient of variation for each factor. This adjusted score was tagged Environmental Barrier-effect Index Value (EBIV). The final ranking of each factor is shown under the column EBIV ${ }^{\mathrm{R}}$ in Table 4.

The final ranking of the factors is, therefore, shown as follows:

EB-a: Lack of government legal enforcement

EB-m: Lack of technological support within organisation

EB-l: Lack of tailor-made training on environmental management
EB-c: Lack of trained staff and expertise

EB-b: Increase in management and operation costs

EB-d: Lack of client support

EB-j: Change of existing practice of company structure and policy

EB-h: Lack of working staff support

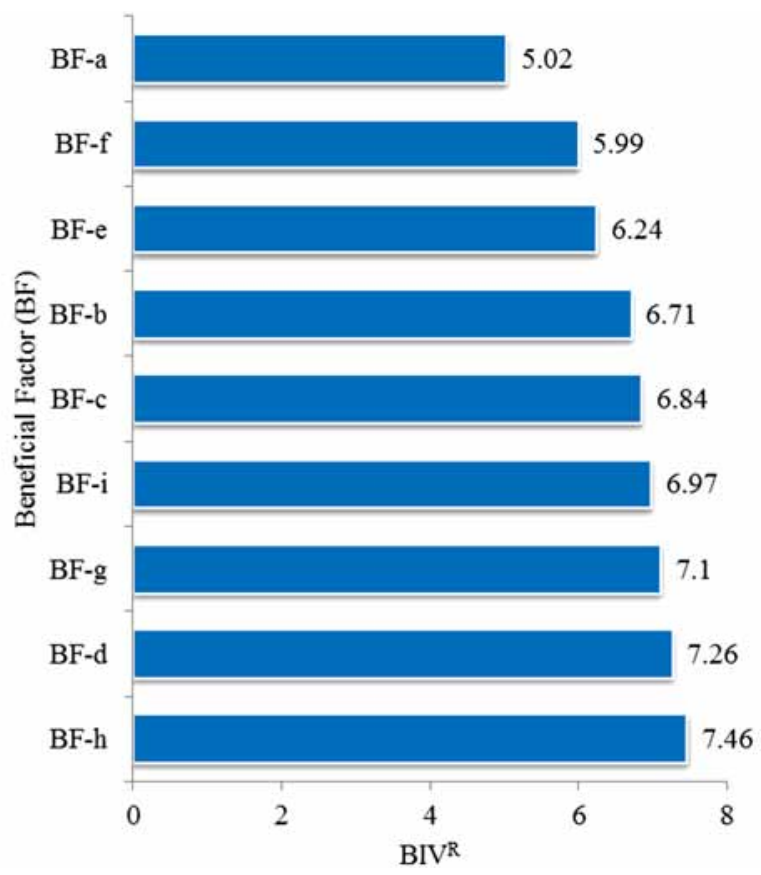

Fig. 1. Ranking profile of the beneficial factors perceived by Nigerian construction professionals

Table 3. Frequency distribution of participant responses to the barriers of implementing EMS in the Nigerian construction industry

\begin{tabular}{cccccc}
\hline $\begin{array}{c}\text { Environ- } \\
\text { mental } \\
\text { Barrier- } \\
\text { effect }\end{array}$ & $\begin{array}{c}\text { Large } \\
\text { Extent }\end{array}$ & $\begin{array}{c}\text { Moderate } \\
\text { Extent }\end{array}$ & $\begin{array}{c}\text { Some } \\
\text { Extent }\end{array}$ & $\begin{array}{c}\text { Minimal } \\
\text { Extent }\end{array}$ & $\begin{array}{c}\text { No } \\
\text { Extent }\end{array}$ \\
\hline Factor & & & & & \\
\hline EB-a & 25 & 6 & 3 & 1 & 2 \\
EB-b & 13 & 11 & 7 & 6 & 0 \\
EB-c & 16 & 9 & 9 & 2 & 1 \\
EB-d & 16 & 3 & 14 & 2 & 2 \\
EB-e & 7 & 13 & 7 & 4 & 6 \\
EB-f & 8 & 9 & 7 & 6 & 7 \\
EB-g & 10 & 9 & 8 & 6 & 4 \\
EB-h & 8 & 9 & 11 & 7 & 2 \\
EB-i & 3 & 10 & 8 & 11 & 5 \\
EB-j & 6 & 12 & 11 & 7 & 1 \\
EB-k & 8 & 8 & 7 & 11 & 3 \\
EB-1 & 20 & 6 & 6 & 5 & 0 \\
EB-m & 15 & 13 & 5 & 4 & 0 \\
\hline
\end{tabular}


EB-g: Difficult co-ordination of environmental performance among multi-tier subcontractors

EB-e: Lack of sub-contractor cooperation

EB-k: Increase in documentation workload

EB-f: Lack of supplier co-operation

EB-i: Time-consuming for improving environmental performance

Based on the results presented above, the factors EB-a (Lack of government legal enforcement), EB-m

Table 4. Calculated Average Barrier Score (ABS) and Barriereffect Index Value (EBIV) for participant responses to barriers of implementing EMS in the Nigerian construction industry

\begin{tabular}{ccccc}
\hline EB & ASS & $\delta$ & EBIV & EBIV $^{\mathrm{R}}$ \\
\hline EB-a & 4.38 & 1.10 & 8.36 & 1 \\
EB-b & 3.84 & 1.08 & 7.40 & 5 \\
EB-c & 4.00 & 1.07 & 7.75 & 4 \\
EB-d & 3.76 & 1.21 & 6.86 & 6 \\
EB-e & 3.30 & 1.33 & 5.77 & 10 \\
EB-f & 3.14 & 1.42 & 5.35 & 12 \\
EB-g & 3.41 & 1.32 & 5.98 & 9 \\
EB-h & 3.38 & 1.17 & 6.26 & 8 \\
EB-i & 2.86 & 1.19 & 5.27 & 13 \\
EB-j & 3.41 & 1.05 & 6.64 & 7 \\
EB-k & 3.19 & 1.29 & 5.66 & 11 \\
EB-1 & 4.11 & 1.11 & 7.81 & 3 \\
EB-m & 4.05 & 0.98 & 8.17 & 2 \\
\hline
\end{tabular}

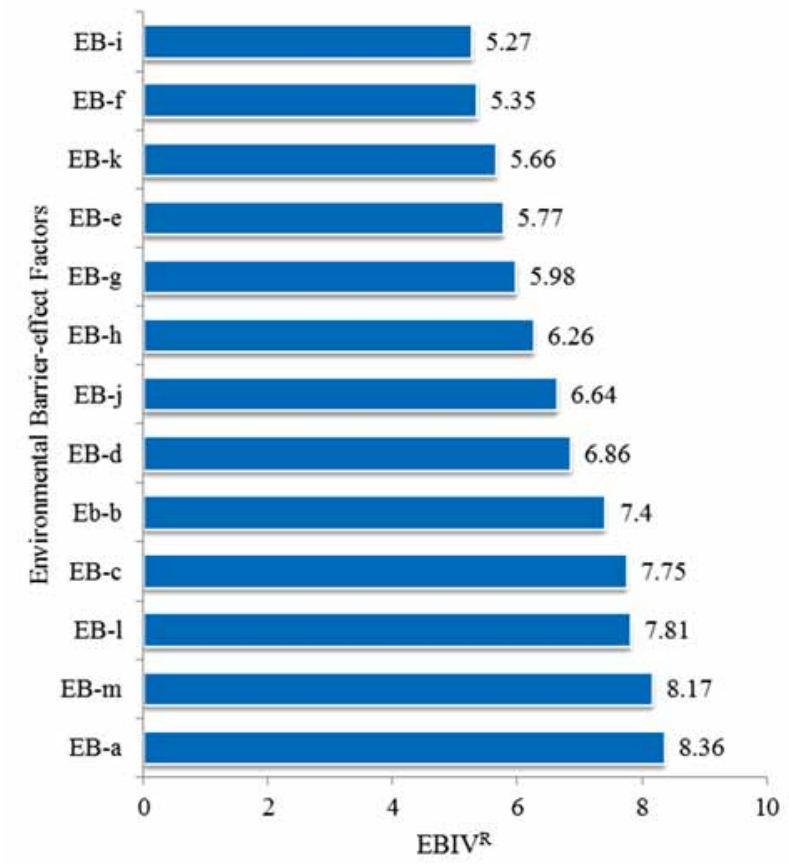

Fig. 2. Ranking profile of the barrier factors perceived by Nigerian construction professionals
(Lack of technological support within organisation) and EB-1 (Lack of tailor-made training on environmental management) emerged as the top three barriers to achieve benefits of environmental management practice ranked by the survey respondents. The lowest ranking barriers were EB-k (Increase in documentation workload), EB-f (Lack of supplier co-operation) and EB-i (Time-consuming for improving environmental performance). Figure 2 is a graphical representation of the final ranking.

\subsection{Implementation of environmental management systems}

A list of strategies for implementing EMS in the construction industry, which could contribute to the growth in the adoption of EMS within Nigeria, was presented to the respondents as follows:

EM-a: Legal requirements on environmental protection

EM-b: Reduction, reuse and recycling of construction and demolition wastes

EM-c: Imposing responsibilities of protecting environment on managerial staff

EM-d: Applying environmentally friendly technology on site

EM-e: Providing in-house training on environmental management

EM-f: Establishing waste management plan

EM-g: Continuous efforts in improving environmental management

EM-h: Inclusion of environmental management in tendering requirements

EM-i: Effective communication on environmental issue between all layers of subcontractors

EM-j: Close supervision at site level

Again respondents were asked to rank these factors into the following categories: Large Extent, Moderate Extent, Some Extent, Minimal Extent and No Extent. Table 5 provides a summary of the distribution of the participant responses.

To determine the overall highest and lowest ranking factors, the weighted average of each factor was calculated. The results of this calculation are shown in Table 6, Average Effectiveness Score (AES). By adopting the same analytical method employed in previous sections, an adjusted score was calculated using the coefficient of variation for each factor. This adjusted score was tagged Effective Index Value (EIV). The final ranking of each factor is shown under the column EIV $^{\mathrm{R}}$ in Table 6.

The final ranking of the factors is, therefore, shown as follows:

EM-i: Effective communication on environmental issue between all layers of subcontractors

EM-j: Close supervision at site level 
Table 5. Frequency distribution of participant responses to the strategies of implementing EMS in the Nigerian construction industry

\begin{tabular}{cccccc}
\hline $\begin{array}{c}\text { Environ- } \\
\text { mental } \\
\begin{array}{c}\text { Mana- } \\
\text { gement } \\
\text { Measures }\end{array}\end{array}$ & $\begin{array}{c}\text { Large } \\
\text { Extent }\end{array}$ & $\begin{array}{c}\text { Moderate } \\
\text { Extent }\end{array}$ & $\begin{array}{c}\text { Some } \\
\text { Extent }\end{array}$ & $\begin{array}{c}\text { Minimal } \\
\text { Extent }\end{array}$ & $\begin{array}{c}\text { No } \\
\text { Extent }\end{array}$ \\
\hline EM-a & 24 & 5 & 6 & 1 & 2 \\
EM-b & 14 & 12 & 6 & 5 & 1 \\
EM-c & 11 & 12 & 11 & 3 & 1 \\
EM-d & 18 & 9 & 7 & 3 & 1 \\
EM-e & 16 & 10 & 8 & 4 & 0 \\
EM-f & 18 & 10 & 7 & 2 & 1 \\
EM-g & 14 & 16 & 4 & 3 & 1 \\
EM-h & 19 & 9 & 5 & 4 & 1 \\
EM-i & 13 & 13 & 12 & 0 & 0 \\
EM-j & 21 & 12 & 3 & 0 & 2 \\
\hline
\end{tabular}

Table 6. Calculated Average Effectiveness Score (ASS) and Effectiveness Index Value (EIV) for participant responses to strategies of implementing EMS in the Nigerian construction industry

\begin{tabular}{ccccc}
\hline EB & ASS & $\delta$ & EIV & EIV $^{\text {R }}$ \\
\hline EB-a & 4.26 & 1.14 & 8.00 & 4 \\
EB-b & 3.87 & 1.13 & 7.30 & 10 \\
EB-c & 3.76 & 1.04 & 7.39 & 9 \\
EB-d & 4.05 & 1.10 & 7.74 & 7 \\
EB-e & 4.00 & 1.03 & 7.90 & 6 \\
EB-f & 4.11 & 1.05 & 8.03 & 3 \\
EB-g & 4.03 & 1.01 & 8.00 & 4 \\
EB-h & 4.08 & 1.13 & 7.68 & 8 \\
EB-i & 4.03 & 0.81 & 8.99 & 1 \\
EB-j & 4.32 & 1.00 & 8.62 & 2 \\
\hline
\end{tabular}

EM-f: Establishing waste management plan

EM-a: Legal requirements on environmental protection

EM-g: Continuous efforts in improving environmental management

EM-e: Providing in-house training on environmental management

EM-d: Applying environmentally friendly technology on site

EM-h: Inclusion of environmental management in tendering requirements

EM-c: Imposing responsibilities of protecting environment on managerial staff

EM-b: Reduction, reuse and recycling of construction and demolition wastes

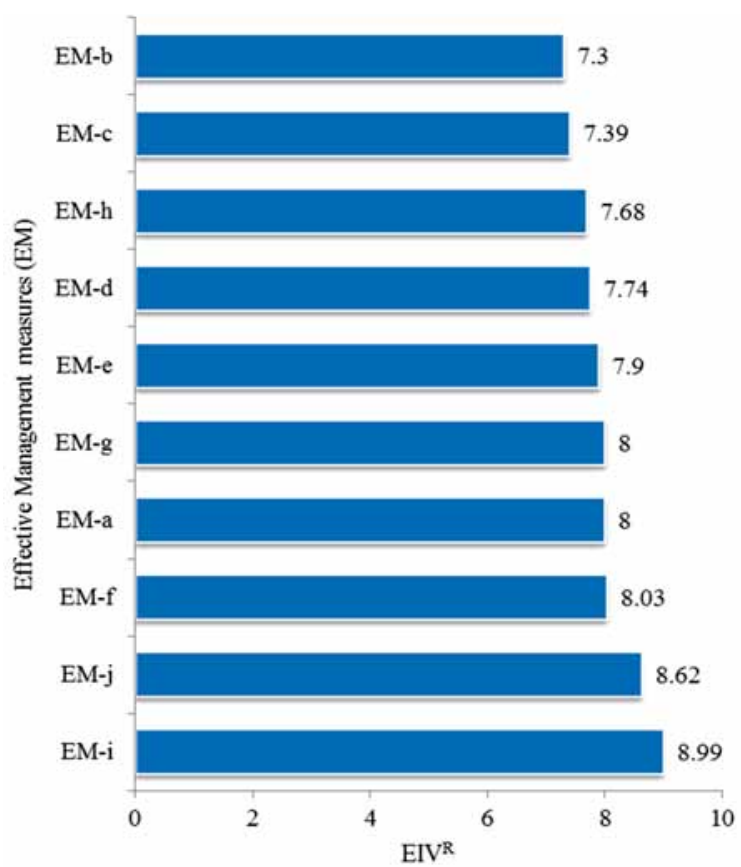

Fig. 3. Ranking profile of the strategic implementation measures perceived by Nigerian construction professionals

Based on the results presented above, the factors EM-i (Effective communication on environmental issue between all layers of subcontractors), EM-j (Close supervision at site level) and EM-f (Establishing waste management plan) emerged as the top three benefits of environmental management practice ranked by the survey respondents. The lowest ranking benefits were EM-h (Inclusion of environmental management in tendering requirements), EM-c (Imposing responsibilities of protecting environment on managerial staff) and EM-b (Reduction, reuse and recycling of construction and demolition wastes) in that order. Figure 3 is a graphical representation of the final ranking.

\section{Discussion}

The study has revealed that environmental protection and waste management are the perceived benefits of implementing EMS in the Nigerian construction industry. This is supported by Zhang et al. (2000) who explored the role of EMS in ensuring the conservation of renewable and non-renewable resources. Previous research has shown that the construction industry in Nigeria has impacted the environment negatively in a number of ways. Aminu et al. (2010) gives a detailed breakdown of the percentage contribution of the building industry in Nigeria to the overall carbon emission, stating that the country is in a vulnerable state.

This study also revealed that the provision of an effective waste management plan is essential to meeting the needs of waste management under the EMS framework, 
just as Poon et al. (2004) discovered in his evaluation of the management of construction waste in housing developments. Poon et al. (2004) also pointed out the ISO 14001 waste management framework and stated that it also helps in reducing the amount of waste generated on a construction project. The implications of these findings include the ability of EMS to increase significant cost savings and reduce the carbon footprint and hazardous impact on the environment (Ofori 1998).

The reuse and recycling of demolition wastes was considered the least relevant implementation strategy to managing waste by Nigerian construction professionals, perhaps because of the dearth of recycling technology within the Nigerian environment (Awopetu et al. 2013). There is still a heavy reliance of landfills in the disposal of waste materials, as construction debris is mostly seen as waste for disposal rather than resources for recycling and reuse (Adebayo 2002; Simion et al. 2013). Thus, the waste management plan may often be based on effective disposal of waste, instead of reuse or recycling of materials (Tannahill, Booth 2012). Aminu et al. (2010) outlined a proposal for the adoption of the Reuse-Reduce-Recycle-Recover model as a means of reversing this trend.

In a similar study carried out by Morrow and Rondinelli (2002), employee motivation was listed as one of the major reasons that organisations implement EMS and this study demonstrated that this factor was considered to have considerable benefit to the implementation of environmental management in Nigeria. One of the possible indicators of this is the amount of training and development that is invested in employees whose organisations implement EMS (Morrow, Rondinelli 2002). This benefit appeals to the employees need for self-actualisation, which is the highest motivating factor based on Maslow's hierarchy of needs (Martin 2005). Many employees are motivated by the nature of the work itself (Martin 2005) and the study suggests that this is the case in many Nigerian construction companies. Morrow and Rondinelli (2002) discuss the implication of this as leading to a higher level of productivity (Martin 2005) within that organisation.

One major barrier unearthed by the study is the limited access to training as a result of lack of technological support within the organisation. Many construction companies in Nigeria are small and medium enterprises (Windapo, Jegede 2013) and, therefore, may be unable to afford the initial capital investment into training materials and software required to implement EMS in the organisation. Sjostrom and Bakens (1999) attribute the high cost of implementation of EMS as one of the reasons for poor implementation of EMS in smaller organisations. As a result, the training might prove irrelevant to the organisation, especially if it is too expensive to apply. Du Plessis (2005) stated that this barrier may pose a demotivating factor to managers and employees and recommends that rigid systems be modified to suit the unique African climate.

Many organisations are reluctant to adopt EMS for the purpose of increasing their overall business competitiveness due to its high cost of implementation (Ervin et al. 2013). There are many reasons for this gap in the Nigerian construction industry, one of which is the aim of clients and contractors to maximise delivery costs by keeping projects under-budget (Windapo, Jegede 2013). This may also lead to corruption within the industry, which could jeopardise the quality of the eventual project deliverables (Windapo, Jegede 2013). In a similar study, Dada (2012) identified some of the factors that directly influenced the choice of procurement methods on Nigerian construction projects, many of which were based on the need for cost certainty, cost reduction and improved project cost performance. Hence, competitive advantage is defined by which organisation can supply the cheapest design option, in sharp contrast to the criteria used in most developed countries like the UK, where value for money ranks equally alongside environmental performance among the key performance indicators on most projects (Chan, A. P. C., Chan A. P. L. 2004).

The lack of adequate technology can be demotivating to organisations' attempts to adopt EMS, and as the study shows, this is the case in Nigeria, based on the high relevance of the lack of technology as a barrier to EMS implementation. Du Plessis (2005) points out the inability of Africa to compete with most continents in the area of technological advancement and the regular supply of basic infrastructure and Nigeria is no exception. As a result of this, many companies are unable to maximise the potential of the technology that is part of the EMS package. This is also responsible for poor investment of these companies in EMS training and development programmes, as earlier explained.

The difficulty in implementing EMS without appropriate technology is more vivid when examined against the complexity of the environmental management process. Christini et al. (2004) outlines the factors that need to be taken into account when implementing an EMS including proper documentation, which is difficult to achieve without the right infrastructure. However, the study concluded that an increase in documentation workload is considered one of the least relevant barriers to the adoption of EMS by Nigerian construction firms. It also concluded that the time consuming nature of the environmental improvement process had the least relevance to the decision to adopt EMS in organisations. This is in contrast to the view presented by Windapo and Jegede (2013) with regards to the priority placed on the value of time by managers of small businesses.

Effective communication on environmental issues between all layers of sub-contractors emerged as the most 
effective environmental management measure in Nigeria based on the findings from the study. This is validated by the case study of Beers Skanka, a USA construction firm, which was discussed by Christini et al. (2004) and which highlighted the importance of communication in EMS policy formation. Effective communication is also the foundation to the Plan-Do-Check-Act Model adapted into an EMS framework by Zhang et al. (2000) as it is one of the tools by which continuous improvement can be achieved (Gupta 1995). Christini et al. (2004) recommended the development of an employee training plan to further enhance the training and development of the supply chain by employing tools such as site inductions and documentation of best practice from previous projects. The essence of this is to encourage the collation of a set of internal standards by which the organisation can improve its environmental management processes. This strategy is useful in developing informal frameworks which may then be tested and passed on to legal institutions for policy formation, as Hill and Bowen (1997) recommend in their analysis of South African implementation of EMS. The strategy is, therefore, relevant in dealing with the lack of formal environmental frameworks highlighted by Aminu et al. (2010).

The need to closely monitor activities on site was highlighted in the study as an important factor in ensuring that suppliers, sub-contractors, and other project stakeholders are aware of the organisation's environmental goals and adhere to the relevant EMS. Christini et al. (2004) explain the success of any approach to environmental management is dependent on the effectiveness of the management strategy employed in coordinating the activities of all relevant stakeholders. The study showed that the challenge with supply chain coordination was seen as a minor barrier to EMS. This implies that supply chain management in Nigeria is not a pressing challenge to environmental performance.

\section{Conclusion}

The construction industry is a major contributor to the GDP of many developing countries and is pivotal to the growth and development of the Nigerian economy. The study has pointed out that the implementation of EMS in the construction industry will contribute to productivity within that sector, as the environment has become a more relevant industry stakeholder. Furthermore, it is important that construction companies are more proactive in dealing with sustainability issues, by ensuring that their activities are more eco-friendly and comply with recognised environmental standards. The findings from the study survey administered among construction professionals in Nigeria has given insight into the major benefits and barriers of EMS and how these insights could be used to generate a more effective implementation strategy within construction organisations.

The study showed that the need for project managers to keep projects under budget and the inability of many organisations to afford the high cost of EMS personnel training are some of the major barriers to EMS adoption. When matched against the identified importance of employee training to the adoption of EMS and its role in increasing employee morale, the need for a strategy that will be less financially cumbersome for small and medium enterprises becomes apparent. The study identified that further research into a framework that accommodates the priority that project managers and clients place on project cost-savings in Nigeria may be more effective in ensuring an increase in the implementation of EMS. In addition, the importance of an employee training plan was highlighted in this study as an effective tool in ensuring continuous development and improvement on environmental management legislation.

The study supported previous research on the effectiveness of ISO 14001 in managing construction waste, which is a major environmental challenge in Nigeria. It is therefore recommended that further studies on a waste management plan based on the Reuse-Reduce-RecycleRecover model in place of the current waste disposal model be carried out. Effective communication in order to effect continuous improvement, and a close monitoring of site activities to ensure that all stakeholders are aware of the importance of environmental management were also identified as enablers to ensure stakeholder adoption of an organisation's environmental strategy.

This study has highlighted a number of benefits that can be reaped from the successful adoption of the EMS framework in the Nigerian construction industry. It is recommended that further research be carried out in this area as an increase in adoption of EMS will not only be of benefit to more organisations in the construction industry, but also to other industry sectors in Nigeria. A welldefined EMS implementation framework in Nigeria may also serve as the basis for developing an environmental management framework for developing countries in SubSaharan Africa and other parts of the world.

\section{References}

Adebayo, A. A. 2002. Sustainable construction in Africa: agenda 21 for sustainable development in developing countries. African Position papers.

Adegbite, B. O. 2013. Assessment and adaptation of an appropriate green building rating system for Nigeria, Journal of Environment and Earth Science 3(1): 1-10.

Aminu, D. Y.; Kandar, M. Z.; Ossen, D. R. 2010. Evoking the green-shift in the building industry for sustainable development in Nigeria, in S. Laryea, R. Leiringer, W. Hughes (Eds.). Proceedings of West Africa Built Environment Research 
(WABER) Conference, 27-28 July 2010, Accra, Ghana, 333343.

Awopetu, M. S.; Coker, A. O.; Awopetu, R. G.; Awopetu, S. O.; Booth, C. A.; Fullen, M. A.; Hammond, F. N.; Tannahill, K. 2013. Reduction, Reuse and recycling of solid waste in the Makurdi Metropolitan area of Nigeria: public opinions and perceptions, International Journal of Education \& Research 1(11): 1-12.

Balzarova, M. A.; Castka, P.; Bamba, C. J.; Sharp, J. M. 2004. How organisational culture impacts on the implementation of ISO 14001:1996 - a UK multiple-case view, Journal of Manufacturing Technology Management 17(1): 89-103.

http://dx.doi.org/10.1108/17410380610639524

BBC News. 2014. Nigeria becomes Africa's biggest economy [online], [cited 15 April 2014]. Available from Internet: http:// www.bbc.co.uk/news/business-26913497

Bohoris, G.; O’Mahony, E. 1994. BS 7750, BS 5750 and the EC's eco management and audit scheme, Industrial Management \& Data Systems 94(2): 3-6.

http://dx.doi.org/10.1108/02635579410055819

Boiral, O.; Sala, J. 1998. Environmental management: should industry adopt IS0 14001, Business Horizons 41(1): 57-64. http://dx.doi.org/10.1016/S0007-6813(98)90065-9

BSI Group. 2014. BSI case study: Costain group [online], [cited 25 April 2014]. Available from Internet: http://www.bsigroup. com/Documents/iso-22301/case-studies/Costain-case-studyUK-EN.pdf

Business Day Online. 2013. How Nigerians use social media [online], [cited 25 April 2014]. Available from Internet: http:// businessdayonline.com/2013/08/how-nigerians-use-socialmedia/\#.U2EEmVfiiso

Carillion Plc. 2014. 2013 Sustainability Report [online], [cited 25 April 2014]. Available from Internet: http://www.carillionplc. com/media/196204/carillion-sr2013-summary.pdf

Castka, P.; Balzarova, M. A. 2008. The impact of ISO 9000 and ISO 14000 on standardisation of social responsibility - an inside perspective, International Journal of Production Economics 113(1): 74-87. http://dx.doi.org/10.1016/j.ijpe.2007.02.048

Chan, A. P. C.; Chan, A. P. L. 2004. Key performance indicators for measuring construction success, Benchmarking: An International Journal 11(2): 203-221.

Christini, G.; Fetsko, M.; Hendrickson, C. 2004. Environmental management systems and ISO 14001 certification for construction firms, Journal of Construction Engineering and Management 130(3): 330-336.

http://dx.doi.org/10.1061/(ASCE)0733-9364(2004)130:3(330)

Czaja, R. F.; Blair, E. A. 2013. Designing surveys: a guide to decisions and procedures. SAGE Publications Incorporated.

Dada, M. O. 2012. Predictors of procurement selection: an investigation of traditional and integrated methods in Nigeria, Journal of Construction in Developing Countries 17(1): 69-83.

Dixon, T.; Colantonio, A.; Shiers, D.; Gallimore, P.; Reed, R.; Wilkinson, S.; Keeping, M. 2007. A green profession? An audit of sustainability tools, techniques and information for RICS members. RICS Report.

Du Plessis, C. 2005. Action for sustainability: preparing an African plan for sustainable building and construction, Building Research \& Information 33(5): 405-415.

http://dx.doi.org/10.1080/09613210500218974

Ervin, D.; Wu, J.; Khanna, M.; Jones, C.; Wirkkala, T. 2013.
Motivations and barriers to corporate environmental management, Business Strategy and the Environment 22(6): 390409. http://dx.doi.org/10.1002/bse.1752

Famiyeh, S.; Kuttu, S.; Anarfo, E. B. 2014. Factors influencing the implementation of environmental management systems in Ghanaian firms, Environmental Management and Sustainable Development 3(2): 18-30.

http://dx.doi.org/10.5296/emsd.v3i2.5893

Fewings, P. 2013. Construction project management: an integrated approach. $2^{\text {nd }} \mathrm{ed}$. London: Routledge.

Freeman, R. E. 1984. Strategic management: a stakeholder approach. Boston: Pitman.

Gupta, M. C. 1995. Environmental management and its impact on the operations function, International Journal of Operations \& Production Management 15(8): 34-51. http://dx.doi.org/10.1108/01443579510094071

Haigh, N.; Griffiths, A. 2009. The natural environment as a primary stakeholder: the case of climate change, Business Strategy and the Environment 18(6): 347-359. http://dx.doi.org/10.1002/bse.602

Hammond, F. N.; Booth, C. A. 2010. Environmental stakeholder management, in E. Chinyio, P. Olomolaiye (Eds.). Construction stakeholder management. Oxford: Wiley-Blackwell, 317-337.

Hill, R. C.; Bowen, P. A. 1997. Sustainable construction: principles and a framework for attainment, Construction Management \& Economics 15(3): 223-239.

http://dx.doi.org/10.1080/014461997372971

Holmes, P. 1985. Nigeria: giant of Africa. Nigeria: National Oil and Chemical Marketing Company of Nigeria.

Idoro, G. I. 2012. The influence of project documents on the outcome of construction projects procured by traditional contracts in Nigeria, Journal of Construction in Developing Countries 17(1): 1-19.

Ilinitch, A. Y.; Soderstrom, N. S.; Thomas, T. E. 1998. Measuring corporate environmental performance, Journal of Accounting and Public Policy 17(4): 383-408.

ISO 2012. The ISO survey of management system standard certifications - survey data.xls [online], [cited 06 July 2014]. Available from Internet: http://www.iso.org/iso/iso-survey.zip

Jolevski, A. 2013. Benefits of ISO14001 certification in the Republic of Macedonia, International Journal of Environment and Sustainable Development 12(2): 168-183. http://dx.doi.org/10.1504/IJESD.2013.052983

Martin, J. 2005. Organizational behaviour and management. Cengage Learning EMEA.

Marzouk, M.; Abdelhamid, M.; Elsheikh, M. 2013. Selecting sustainable building materials using system dynamics and ant colony optimization, Journal of Environmental Engineering and Landscape Management 21(4): 237-247. http://dx.doi.org/10.3846/16486897.2013.788506

Medineckiene, M.; Turskis, Z.; Zavadskas, E. K. 2010. Sustainable construction taking into account the building impact on the environment, Journal of Environmental Engineering and Landscape Management 18(2): 118-127. http://dx.doi.org/10.3846/jeelm.2010.14

Morrow, D.; Rondinelli, D. 2002. Adopting corporate environmental management systems: motivations and results of ISO 14001 and EMAS certification, European Management Journal 20(2): 159-171. http://dx.doi.org/10.1016/S0263-2373(02)00026-9 
Ofori, G. 1998. Sustainable construction: principles and a framework for attainment-comment, Construction Management \& Economics 16(2): 141-145. http://dx.doi.org/10.1080/014461998372448

Ofori, G. 2006. Revaluing construction in developing countries: a research agenda, Journal of Construction in Developing Countries 11(1): 1-16.

Oke, S. A. 2004. A review on environmental research, Journal of Environmental Engineering and Landscape Management 12(4): 153-157.

Poon, C.; Yu, A. T.; Jaillon, L. 2004. Reducing building waste at construction sites in Hong Kong, Construction Management and Economics 22(5): 461-470. http://dx.doi.org/10.1080/0144619042000202816

Rio Tinto. 2008. 2008 Annual Report [online], [cited 27 April 2014]. Available from Internet: http://www.riotinto.com/annualreport2008/pdfs/AnnualReport2008.pdf

Shen, L.; Tam, V. W. 2002. Implementation of environmental management in the Hong Kong construction industry, International Journal of Project Management 20(7): 535-543.

Simion, I. M.; Fortuna, M. E.; Bonoli, A.; Gavrilescu, M. 2013. Comparing environmental impacts of natural inert and recycled construction and demolition waste processing using
LCA, Journal of Environmental Engineering and Landscape Management 21(4): 273-287. http://dx.doi.org/10.3846/164 86897.2013.852558

Sjostrom, C.; Bakens, W. 1999. CIB Agenda 21 for sustainable construction: why, how and what, Building Research \& Information 27(6): 347-353.

http://dx.doi.org/10.1080/096132199369174

Tannahill, K.; Booth, C. A. 2012. Linkages of waste management strategies and climate change issues, in C. A. Booth, F. Hammond, J. E. Lamond, D. G. Proverbs (Eds.). Solutions to climate change challenges in the built environment. Oxford: Wiley-Blackwell, 207-221.

Wenk, M. S. 2004. EU's eco-management and audit scheme, Environmental Quality Management 14(1): 59-70. http://dx.doi.org/10.1002/tqem.20026

Windapo, A. O.; Jegede, O. P. 2013. A study of health, safety and environment (HSE) practices of Nigerian construction companies, The Professional Builder 4(1): 92-103.

Zhang, Z. H.; Shen, L. Y.; Love, P. E.; Treloar, G. 2000. A framework for implementing ISO 14000 in construction, Environmental Management and Health 11(2): 139-149. http://dx.doi.org/10.1108/09566160010321541

Victoria O. OWOLANA is an Assistant Project Manager at Courtney Michael Partnership, Nigeria and a former postgraduate student at the University of the West of England, Bristol (UK). Research interests: architecture, project management, construction law and procurement, sustainability, and environmental management.

Colin A. BOOTH Dr., Associate Professor of Sustainability, is Associate Head of Research and Scholarship in the Faculty of Environment and Technology at the University of the West of England, Bristol (UK). Publications: author/co-author of several books and $~ 140$ scientific papers and chapters. Research interests: sustainability, environmental management, climate change mitigation and adaptation strategies, water resources management, and built environment studies. 